\title{
Clinical Outcomes of T4a Papillary Thyroid Cancer With Recurrent Laryngeal Nerve Involvement: A Retrospective Analysis
}

Han-Seul Na

Pusan National University Hospital

Hyun-Keun Kwon

Pusan National University Hospital

Sung-Chan Shin

Pusan National University Hospital

Yong-II Cheon

Pusan National University Hospital

Myeonggu Seo

Pusan National University Hospital

Jin-Choon Lee

Pusan National University Yangsan Hospital

Eui-Suk Sung

Pusan National University Yangsan Hospital

Minhyung Lee

Pusan National University Yangsan Hospital

In-Joo Kim

Pusan National University Hospital

Bo-Hyun Kim

Pusan National University Hospital

Byung-Joo Lee ( $\nabla$ voiceleebj@gmail.com )

Pusan National University Hospital

\section{Research Article}

Keywords: VCP, PTC, RLN, thyroid

Posted Date: December 28th, 2020

DOI: https://doi.org/10.21203/rs.3.rs-129560/v1 
License: (c) (1) This work is licensed under a Creative Commons Attribution 4.0 International License. Read Full License

Version of Record: A version of this preprint was published at Scientific Reports on March 23rd, 2021. See the published version at https://doi.org/10.1038/s41598-021-86226-x. 


\section{Abstract}

Preoperative vocal cord palsy (VCP) may indicate locally invasive papillary thyroid cancer (PTC); using this relationship, we evaluated the clinical outcomes and risk factors for recurrence in post-thyroidectomy T4a PTC patients with recurrent laryngeal nerve (RLN) involvement. We retrospectively investigated thyroidectomy patients, recorded their clinical factors, recurrence rate, and pathological findings, and analysed the relationship between recurrence rate and clinical factors. Of 72 patients, 37 (51\%) had preoperative VCP and 35 (49\%) had normal preoperative vocal cord movement with confirmed intraoperative RLN invasion. Tracheal and esophageal invasion was observed in 13 (18\%) and $15(21 \%)$ patients, respectively. Thyroid cancer recurred in $18(25 \%)$ patients over 58 months, resulting in $2(3 \%)$ deaths. Recurrence was not associated with surgical extent, organ invasion, enlarged tumour size, or lymph node infiltration $(p>0.05)$. The recurrence rate was significantly higher in patients with positive resection margins $(p<0.05)$. T4a PTC patients with RLN involvement showed a poor prognosis. The recurrence rate was not affected by preoperative VCP, intraoperative detection of RLN invasion, nerve resection, nerve preservation by shaving, lymph node metastasis, or tracheal or esophageal invasion. The most important prognostic factor for recurrence was a positive resection margin.

\section{Introduction}

Papillary thyroid carcinoma (PTC) is the most common type of thyroid cancer. Differentiated thyroid cancer, especially papillary microcarcinoma, has an excellent prognosis with very low mortality ${ }^{1}$. However, according to the American Thyroid Association guidelines, PTC patients with macroscopic tumour invasion, incomplete resection, distant metastasis, and thyroglobulinaemia are classified as a high-risk group for poor prognoses².

The invasion of adjacent structures by PTC, with extrathyroidal extension, is termed locally invasive thyroid cancer, and it presents differently depending on the anatomical structures it invades, which influences the clinical presentation and therapeutic consequences ${ }^{3,4}$. In this regard, invasion of the recurrent laryngeal nerve (RLN) is one of the main predictors of poor prognosis in PTC patients; in a previous study, tumour recurrence occurred 3 times higher in RLN-involved patients than control-group ${ }^{5}$. RLN invasion can affect the surrounding vital organs, such as, trachea, and/or esophagus, which increases the range of surgery and worsens the prognosis ${ }^{3}$. For this reason, RLN invasion corresponds to a grade of T4a as per the American Joint Committee on Cancer classification.

It is possible to predict RLN invasion in PTC patients by checking for vocal cord palsy (VCP) before surgery. Previous studies reported that only $1-3 \%$ of patients with a thyroid tumour exhibited preoperative $V C P^{6,7}$. However, even if vocal cord movements are normal before surgery, RLN invasion may be observed during the operation. There are controversies regarding whether the RLN should be resected when its involvement is suspected preoperatively or confirmed intraoperatively. When VCP is observed before surgery, the RLN tends to be sacrificed in the majority of cases. In contrast, when VCP is not observed 
preoperatively, there is a tendency to attempt to preserve the nerve as much as possible; however, the tumour may not be completely removed with this approach, resulting in a higher risk of recurrence.

The thyroid cancer recurrence rate has been reported to be $31.4 \%$ in cases with RLN involvement ${ }^{5}$. Nevertheless, there is a lack of studies wherein potential predictors of PTC recurrence after surgery in patients with RLN involvement are evaluated. Therefore, our study aimed to evaluate the clinical outcomes and risk factors associated with thyroid cancer recurrence after thyroidectomy in T4a PTC patients with RLN involvement.

\section{Results}

Table 1 describes the characteristics of all our patients. Eighteen patients $(25.0 \%)$ exhibited confirmed recurrence during the follow-up period. The sites of recurrence included: $6(33.3 \%)$ patients on the central neck, $10(55.6 \%)$ on the lateral neck, $7(38.9 \%)$ with distant recurrence, and $5(27.8 \%)$ with recurrence at multiple sites. 
Table 1

Clinical characteristics of 72 patients with RLN invasion.

\begin{tabular}{|c|c|c|c|c|c|}
\hline Characteristics & & Overall & Recurrence & $\begin{array}{l}\text { No } \\
\text { recurrence }\end{array}$ & $\begin{array}{l}\mathrm{p}- \\
\text { value }\end{array}$ \\
\hline $\mathrm{n}$. & & 72 & 18 & 54 & \\
\hline $\begin{array}{l}\text { f/u time month } \\
\text { (median [IQR]) }\end{array}$ & & $\begin{array}{l}58.00[30.25 \\
\sim 83.00]\end{array}$ & $\begin{array}{l}38.50 \\
{[31.00,} \\
59.00]\end{array}$ & $\begin{array}{l}64.50 \\
{[28.75,} \\
93.00]\end{array}$ & 0.091 \\
\hline \multirow[t]{2}{*}{ Sex (\%) } & $\mathrm{F}$ & $56(77.8)$ & $11(19.64)$ & $45(80.36)$ & 0.098 \\
\hline & $M$ & $16(22.2)$ & $7(43.75)$ & $9(56.25)$ & \\
\hline Age (mean (SD)) & & $57.59(14.17)$ & $\begin{array}{l}57.52 \\
(14.47)\end{array}$ & $\begin{array}{l}57.61 \\
(14.20)\end{array}$ & 0.982 \\
\hline Height (mean (SD)) & & $159.48(7.86)$ & $\begin{array}{l}161.75 \\
(8.16)\end{array}$ & $\begin{array}{l}158.71 \\
(7.68)\end{array}$ & 0.176 \\
\hline $\begin{array}{l}\text { Body weight (mean } \\
\text { (SD)) }\end{array}$ & & $61.63(11.89)$ & $\begin{array}{l}65.43 \\
(15.82)\end{array}$ & $\begin{array}{l}60.34 \\
(10.08)\end{array}$ & 0.213 \\
\hline BMI (mean (SD)) & & $24.12(3.38)$ & $24.81(4.07)$ & $23.89(3.12)$ & 0.390 \\
\hline \multirow{3}{*}{$\begin{array}{l}\text { Operative method } \\
(\%)\end{array}$} & $\mathrm{HT}$ & $1(1.4)$ & $0(0.0)$ & $1(100)$ & 0.836 \\
\hline & TT /c CND & $43(59.7)$ & $10(23.26)$ & $33(76.74)$ & \\
\hline & $\begin{array}{l}\text { TT /c CND } \\
\text { /c LND }\end{array}$ & $28(38.9)$ & $8(28.57)$ & $20(71.43)$ & \\
\hline \multirow[t]{2}{*}{ RAl dose (\%) } & $<150$ & $17(26.2)$ & $4(23.53)$ & $13(76.47)$ & 1.000 \\
\hline & $\geq 150$ & $48(73.8)$ & $13(27.08)$ & $35(72.92)$ & \\
\hline \multirow{2}{*}{$\begin{array}{l}\text { Tg level post } \\
\text { ablation (\%) }\end{array}$} & $\leq 1$ & $22(34.4)$ & $3(13.64)$ & $19(86.36)$ & 0.137 \\
\hline & $>1$ & $42(65.6)$ & $14(33.33)$ & $28(66.67)$ & \\
\hline \multirow[t]{2}{*}{ Pre op. VCP (\%) } & yes & $37(51.4)$ & $10(27.03)$ & 27 (72.97) & 0.788 \\
\hline & no & $35(48.6)$ & $8(22.86)$ & $27(77.14)$ & \\
\hline \multirow[t]{2}{*}{ RLN direction (\%) } & Rt. & $32(44.4)$ & $8(25.00)$ & $24(75.00)$ & 1.000 \\
\hline & Lt. & $39(54.1)$ & $10(25.64)$ & $29(74.36)$ & \\
\hline Tumor size (\%) & $\leq 20 \mathrm{~mm}$ & $39(54.2)$ & 7 (17.95) & $32(82.05)$ & 0.175 \\
\hline
\end{tabular}

tRLN : Recurrent laryngeal nerve, IQR : Inter quartile range, SD : Standard deviation, RAI : Radioactive iodine, VCP : Vocal cord palsy 


\begin{tabular}{|c|c|c|c|c|c|c|}
\hline \multirow[t]{2}{*}{ Characteristics } & & Overall & Recurrence & $\begin{array}{l}\text { No } \\
\text { recurrence }\end{array}$ & $\begin{array}{l}\mathrm{p}- \\
\text { value }\end{array}$ & $\begin{array}{l}{ }^{*} p \\
< \\
0.05\end{array}$ \\
\hline & $>20 \mathrm{~mm}$ & $33(45.8)$ & 11 (33.33) & 22 (66.67) & & \\
\hline \multirow{2}{*}{$\begin{array}{l}\text { Resection margin } \\
(\%)\end{array}$} & clear & $39(54.2)$ & $5(12.82)$ & 34 (87.18) & 0.014 & * \\
\hline & involved & $33(45.8)$ & 13 (39.39) & $20(60.61)$ & & \\
\hline \multirow{2}{*}{$\begin{array}{l}\text { Intra op. RLN } \\
\text { resection (\%) }\end{array}$} & yes & 47 (65.3) & 15 (31.91) & 32 (68.09) & 0.088 & \\
\hline & no & $25(34.7)$ & $3(12.00)$ & $22(88.00)$ & & \\
\hline \multirow{2}{*}{$\begin{array}{l}\text { RLN anastomosis } \\
(\%)\end{array}$} & yes & $7(9.7)$ & $1(14.29)$ & $6(85.71)$ & 0.672 & \\
\hline & no & 65 (90.3) & $17(26.15)$ & 48 (73.85) & & \\
\hline \multirow[t]{2}{*}{ Multifocality (\%) } & yes & $25(34.7)$ & $6(24.00)$ & $19(76.00)$ & 1.000 & \\
\hline & no & $47(65.3)$ & $12(25.53)$ & 35 (74.47) & & \\
\hline \multirow{2}{*}{$\begin{array}{l}\text { Trachea invasion } \\
(\%)\end{array}$} & yes & $13(18.1)$ & $4(30.77)$ & $9(69.23)$ & 0.725 & \\
\hline & no & $59(81.9)$ & $14(23.73)$ & 45 (76.27) & & \\
\hline \multirow{2}{*}{$\begin{array}{l}\text { Esophagus } \\
\text { invasion (\%) }\end{array}$} & yes & $15(20.8)$ & $5(33.33)$ & $10(66.67)$ & 0.504 & \\
\hline & no & 57 (79.2) & $13(22.81)$ & 44 (77.19) & & \\
\hline \multirow[t]{2}{*}{ Central meta (\%) } & yes & $44(61.1)$ & $10(22.73)$ & 34 (77.27) & 0.589 & \\
\hline & no & $28(38.9)$ & $8(28.57)$ & $20(71.43)$ & & \\
\hline $\begin{array}{l}\text { N. of central meta } \\
(\text { mean (SD)) }\end{array}$ & & $2.10(2.66)$ & $3.11(4.17)$ & $1.76(1.85)$ & 0.198 & \\
\hline \multirow[t]{2}{*}{ Lateral meta (\%) } & yes & $28(38.9)$ & $8(28.57)$ & $20(71.43)$ & 0.589 & \\
\hline & no & $44(61.1)$ & $10(22.73)$ & 34 (77.27) & & \\
\hline
\end{tabular}

The median follow-up time was 58 months, females were predominant, and the median patient age was 57.59 years. We also collected height, weight, and body mass index as basic information.

One patient chose to undergo hemithyroidectomy despite having T4a PTC because they wished to preserve their remaining thyroid lobes. We considered the postoperative radioactive iodine (RAI) dose as a categorical parameter, wherein 48 patients $(73.8 \%)$ underwent RAl therapy with over $150 \mathrm{mCi}$ and 24 patients underwent RAl therapy with less than $150 \mathrm{mCi}$. 
A previous study on locally invasive thyroid cancer found that post-ablation thyroglobulin ( $\mathrm{Tg}$ ) levels that were higher than 1 contributed to a significantly increased recurrence rate ${ }^{8}$. In this study, the $\mathrm{Tg}$ levels of post-ablation varied between 1, less than 1, or more than 1 . However, the correct post-ablation $\mathrm{Tg}$ values could not be determined in eight patients $(11.1 \%)$, as RAl therapy was performed at other hospitals. Among the remaining patients, the post-ablation Tg levels were less than 1 in $34.4 \%$ of the cases and exceeded 1 in $73.8 \%$ of the cases. There was no significant association between post-ablation Tg level and PTC recurrence $(p>0.05)$.

A total of 37 patients $(51.4 \%)$ had VCP before surgery and 35 patients $(48.6 \%)$ did not. The RLN invasion was similar on both sides of the body, wherein the right RLN was involved in 32 patients $(44.4 \%)$ and the left side was involved in 39 patients $(54.1 \%)$; one patient had bilateral invasions. The median tumour size $23.28 \mathrm{~mm}$, and the category value was divided into $2 \mathrm{~cm}$ or less and $2 \mathrm{~cm}$ or more. Twenty-five patients (34.7\%) underwent shaving after we intraoperatively confirmed RLN invasion, and the remaining patients underwent nerve resection. Of these, we immediately performed nerve anastomoses in 7 patients. In addition to RLN involvement, $13(18.1 \%)$ and 15 patients (20.8\%) showed tracheal and esophageal invasion, respectively, while $44(61.1 \%)$ and $28(38.9 \%)$ patients showed central and lateral neck metastasis, respectively. The presence of central and lateral lymph node $(L N)$ metastasis was not associated with PTC recurrence. The number of central LN metastases was not significantly different between patients with and without PTC recurrence.

After the final pathological evaluation, 39 patients (54.2\%) showed clear resection margins and 33 $(45.8 \%)$ showed positive/involved resection margins. Of the 39 patients with clear margins, $5(12.82 \%)$ showed a recurrence and the remaining $34(87.18 \%)$ did not. Of the 33 patients with involved margins, 13 $(39.39 \%)$ relapsed and 20 (60.61\%) showed no recurrence--this indicated a relatively high recurrence rate in the involved-margin group $(p=0.014)$. In a simple analysis of these parameters, which did not account for survival time, only the positive resection margins were statistically significant.

Table 2 compares the preoperative VCP group and the intraoperative RLN-invasion group. There was no significant difference in the recurrence rates between the two groups $(p>0.05)$. There was also no difference between the two groups in terms of tumour size, resection margin, RLN anastomosis, ETE, multifocality, and tracheal or esophageal invasion $(p>0.05)$. Likewise, there was no difference between the two groups regarding the presence of central and lateral LN metastasis, and the number of lateral LN metastases. However, the mean number of central LN metastases was significantly higher in the preoperative VCP group (2.76) compared to the no-VCP group $(1.40 ; p=0.028)$. 
Table 2

Comparison of the pre-operative VCP group with non pre-operative VCP group.

\begin{tabular}{|c|c|c|c|c|c|c|}
\hline Variable & & Overall & $\begin{array}{l}\text { Pre-operative } \\
\text { VCP }\end{array}$ & $\begin{array}{l}\text { Non pre- } \\
\text { operative VCP }\end{array}$ & $\begin{array}{l}\mathrm{p}- \\
\text { value }\end{array}$ & $\begin{array}{l}* p< \\
0.05\end{array}$ \\
\hline $\mathrm{n}$. & & 72 & 37 & 35 & & \\
\hline \multirow[t]{2}{*}{ Recur (\%) } & yes & $\begin{array}{l}18 \\
(25.0)\end{array}$ & $10(27.0)$ & $8(22.9)$ & 0.788 & \\
\hline & no & $\begin{array}{l}54 \\
(75.0)\end{array}$ & $27(73.0)$ & $27(77.1)$ & & \\
\hline \multirow[t]{2}{*}{ Tumor size (\%) } & $\begin{array}{l}\leq \\
20 \mathrm{~mm}\end{array}$ & $\begin{array}{l}39 \\
(54.2)\end{array}$ & $19(51.4)$ & $20(57.1)$ & 0.644 & \\
\hline & $20 \mathrm{~mm}$ & $\begin{array}{l}33 \\
(45.8)\end{array}$ & $18(48.6)$ & $15(42.9)$ & & \\
\hline \multirow[t]{2}{*}{ Resection margin (\%) } & clear & $\begin{array}{l}39 \\
(54.2)\end{array}$ & $17(45.9)$ & $22(62.9)$ & 0.165 & \\
\hline & involved & $\begin{array}{l}33 \\
(45.8)\end{array}$ & $20(54.1)$ & $13(37.1)$ & & \\
\hline \multirow[t]{2}{*}{$\begin{array}{l}\text { Intra op. RLN resection } \\
(\%)\end{array}$} & yes & $\begin{array}{l}47 \\
(65.3)\end{array}$ & $31(83.8)$ & $16(45.7)$ & 0.001 & * \\
\hline & no & $\begin{array}{l}25 \\
(34.7)\end{array}$ & $6(16.2)$ & $19(54.3)$ & & \\
\hline \multirow[t]{2}{*}{ RLN anastomosis (\%) } & yes & $7(9.7)$ & $2(5.4)$ & $5(14.3)$ & 0.254 & \\
\hline & no & $\begin{array}{l}65 \\
(90.3)\end{array}$ & $35(94.6)$ & $30(85.7)$ & & \\
\hline \multirow[t]{2}{*}{ ETE (\%) } & yes & $\begin{array}{l}66 \\
(91.7)\end{array}$ & $35(94.6)$ & $31(88.6)$ & 0.423 & \\
\hline & no & $6(8.3)$ & $2(5.4)$ & $4(11.4)$ & & \\
\hline \multirow[t]{2}{*}{ Multifocality (\%) } & yes & $\begin{array}{l}25 \\
(34.7)\end{array}$ & $15(40.5)$ & $10(28.6)$ & 0.329 & \\
\hline & no & $\begin{array}{l}47 \\
(65.3)\end{array}$ & $22(59.5)$ & $25(71.4)$ & & \\
\hline \multirow[t]{2}{*}{ Trachea invasion (\%) } & yes & $\begin{array}{l}13 \\
(18.1)\end{array}$ & $9(24.3)$ & $4(11.4)$ & 0.222 & \\
\hline & no & $\begin{array}{l}59 \\
(81.9)\end{array}$ & $28(75.7)$ & $31(88.6)$ & & \\
\hline
\end{tabular}

† VCP : Vocal cord palsy, RLN : Recurrent laryngeal nerve, ETE : Extrathyroidal extension, SD : Standard deviation 


\begin{tabular}{|c|c|c|c|c|c|c|}
\hline Variable & & Overall & $\begin{array}{l}\text { Pre-operative } \\
\text { VCP }\end{array}$ & $\begin{array}{l}\text { Non pre- } \\
\text { operative VCP }\end{array}$ & $\begin{array}{l}\mathrm{p}- \\
\text { value }\end{array}$ & $\begin{array}{l}* p< \\
0.05\end{array}$ \\
\hline \multirow[t]{2}{*}{$\begin{array}{l}\text { Esophagus invasion } \\
(\%)\end{array}$} & yes & $\begin{array}{l}15 \\
(20.8)\end{array}$ & 9 (24.3) & $6(17.1)$ & 0.566 & \\
\hline & no & $\begin{array}{l}57 \\
(79.2)\end{array}$ & $28(75.7)$ & $29(82.9)$ & & \\
\hline \multirow[t]{2}{*}{ Central meta (\%) } & yes & $\begin{array}{l}44 \\
(61.1)\end{array}$ & $26(70.3)$ & $18(51.4)$ & 0.147 & \\
\hline & no & $\begin{array}{l}28 \\
(38.9)\end{array}$ & $11(29.7)$ & $17(48.6)$ & & \\
\hline $\begin{array}{l}\text { N. of central meta } \\
(\text { mean }(S D))\end{array}$ & & $\begin{array}{l}2.10 \\
(2.66)\end{array}$ & $2.76(3.04)$ & $1.40(2.00)$ & 0.028 & * \\
\hline \multirow[t]{2}{*}{ Lateral meta (\%) } & yes & $\begin{array}{l}28 \\
(38.9)\end{array}$ & $18(48.6)$ & $10(28.6)$ & 0.095 & \\
\hline & no & $\begin{array}{l}44 \\
(61.1)\end{array}$ & $19(51.4)$ & $25(71.4)$ & & \\
\hline $\begin{array}{l}\text { N. of lateral meta } \\
(\text { mean (SD)) }\end{array}$ & & $\begin{array}{l}2.03 \\
(4.04)\end{array}$ & $2.59(4.21)$ & $1.43(3.82)$ & 0.222 & \\
\hline
\end{tabular}

A total of 47 patients (65.3\%) underwent RLN resection and 25 did not (34.7\%). In the preoperative VCP group, a majority of patients $(31 ; 83.8 \%)$ underwent RLN resection. However, in the intraoperatively detected RLN-invasion group, the RLN was sacrificed in 16 patients (45.7\%) to preserve it as far as possible. The rate of resection without preserving the RLN was relatively high in the preoperative VCP group; this result was statistically significant $(p=0.001)$.

In the univariate analysis, we found two parameters--resection margin and the number of central LN metastases- - to be significant risk factors for recurrence-free survival (RFS) ( $p<0.05$; Table 3). Sex, age, height, body weight, body mass index, RAl dose, post-ablation Tg level, preoperative VCP, RLN direction, tumour size, RLN resection, RLN anastomosis, ETE, multifocality, tracheal and esophageal invasion, and lateral LN metastasis were not significantly associated with recurrence as per our statistical analysis ( $p$ > 0.05 ). In the multivariate analysis that included five parameters with $p$-values of less than 0.2 , we only found one independent variable--resection margin involvement-- as a risk factor for RFS (hazard ratio $=3.331$ [confidence interval 1.017-10.915]; $p=0.047$ ). 
Table 3

Factors predictive of recurrence by univariate and multivariate analysis.

\begin{tabular}{|c|c|c|c|c|c|c|}
\hline \multirow[t]{2}{*}{ Variable } & \multicolumn{3}{|c|}{ Univariate analysis } & \multicolumn{3}{|c|}{ Multiivariate analysis } \\
\hline & $\mathrm{HR}[95 \% \mathrm{Cl}]$ & $\begin{array}{l}\mathrm{p}- \\
\text { value }\end{array}$ & $\begin{array}{l}* p< \\
0.05\end{array}$ & $\mathrm{HR}[95 \% \mathrm{Cl}]$ & $\begin{array}{l}\mathrm{p}- \\
\text { value }\end{array}$ & $\begin{array}{l}* \mathrm{p}< \\
0.05\end{array}$ \\
\hline Sex $=M(\%)$ & $\begin{array}{l}1.784[0.683 \\
4.661]\end{array}$ & 0.237 & & & & \\
\hline Age (mean (SD)) & $\begin{array}{l}0.999[0.965 \\
1.035]\end{array}$ & 0.957 & & & & \\
\hline Height (mean (SD)) & $\begin{array}{l}1.022[0.965, \\
1.082]\end{array}$ & 0.465 & & & & \\
\hline $\begin{array}{l}\text { Body weight (mean } \\
\text { (SD)) }\end{array}$ & $\begin{array}{l}1.024[0.986, \\
1.064]\end{array}$ & 0.222 & & & & \\
\hline BMI (mean (SD)) & $\begin{array}{l}1.070[0.922, \\
1.241]\end{array}$ & 0.372 & & & & \\
\hline RAl dose $\geq 150$ (\%) & $\begin{array}{l}1.084[0.353 \\
3.329]\end{array}$ & 0.888 & & & & \\
\hline $\begin{array}{l}\text { Tg level post ablation > } \\
1(\%)\end{array}$ & $\begin{array}{l}2.759[0.791 \\
9.627]\end{array}$ & 0.112 & & $\begin{array}{l}1.838[0.494 \\
6.839]\end{array}$ & 0.364 & \\
\hline Pre op. VCP = no (\%) & $\begin{array}{l}0.888[0.350 \\
2.253]\end{array}$ & 0.803 & & & & \\
\hline RLN direction = Lt. $(\%)$ & $\begin{array}{l}1.221[0.481 \\
3.098]\end{array}$ & 0.674 & & & & \\
\hline Tumor size > 20 (\%) & $\begin{array}{l}1.626[0.626 \\
4.225]\end{array}$ & 0.318 & & & & \\
\hline $\begin{array}{l}\text { Resection margin } \\
\text { positive (\%) }\end{array}$ & $\begin{array}{l}2.982[1.056, \\
8.418]\end{array}$ & 0.039 & * & $\begin{array}{l}3.331[1.017 \\
10.915]\end{array}$ & 0.047 & * \\
\hline $\begin{array}{l}\text { Intra op. RLN resection } \\
=\text { no }(\%)\end{array}$ & $\begin{array}{l}0.395[0.114 \\
1.367]\end{array}$ & 0.143 & & $\begin{array}{l}0.428[0.091 \\
2.001]\end{array}$ & 0.281 & \\
\hline $\begin{array}{l}\text { RLN anastomosis = no } \\
(\%)\end{array}$ & $\begin{array}{l}2.164[0.288 \\
16.279]\end{array}$ & 0.453 & & & & \\
\hline $\mathrm{ETE}=$ no $(\%)$ & $\begin{array}{l}0.925[0.122 \\
6.982]\end{array}$ & 0.939 & & & & \\
\hline Multifocality = no (\%) & $\begin{array}{l}1.073[0.402 \\
2.861]\end{array}$ & 0.888 & & & & \\
\hline $\begin{array}{l}\text { Trachea invasion = no } \\
(\%)\end{array}$ & $\begin{array}{l}0.786[0.258, \\
2.391]\end{array}$ & 0.671 & & & & \\
\hline
\end{tabular}

† HR : Hazard ratio, SD : Standard deviation, RAl : Radioactive iodine, Tg : Thyroglobulin, VCP : Vocal cord palsy, RLN : Recurrent laryngeal nerve, ETE : Extrathyroidal extension 


\begin{tabular}{|c|c|c|c|c|c|}
\hline \multirow{2}{*}{$\begin{array}{l}\text { Variable } \\
\text { Esophagus invasion = } \\
\text { no (\%) }\end{array}$} & \multicolumn{3}{|c|}{ Univariate analysis } & \multicolumn{2}{|c|}{ Multiivariate analysis } \\
\hline & $\begin{array}{l}0.596[0.212 \\
1.676]\end{array}$ & 0.327 & & & \\
\hline $\begin{array}{l}\text { Central node meta = no } \\
(\%)\end{array}$ & $\begin{array}{l}1.050[0.411, \\
2.679]\end{array}$ & 0.919 & & & \\
\hline $\begin{array}{l}\text { N. of central meta } \\
(\text { mean }(S D))\end{array}$ & $\begin{array}{l}1.196[1.049 \\
1.364]\end{array}$ & 0.007 & * & $\begin{array}{l}1.120[0.992, \\
1.264]\end{array}$ & 0.068 \\
\hline $\begin{array}{l}\text { Lateral node meta }=\text { no } \\
(\%)\end{array}$ & $\begin{array}{l}0.704[0.277, \\
1.787]\end{array}$ & 0.460 & & & \\
\hline $\begin{array}{l}\text { N. of lateral meta (mean } \\
\text { (SD)) }\end{array}$ & $\begin{array}{l}0.859[0.701 \\
1.052]\end{array}$ & 0.142 & & $\begin{array}{l}0.801[0.636 \\
1.008]\end{array}$ & 0.059 \\
\hline
\end{tabular}

Figure 1 shows a Kaplan-Meier survival curve depicting the RFS of patients with involved resection margins. Of the 18 patients who showed recurrence during follow-up, 5 and 13 belonged to the clear- and involved-margin groups, respectively. As compared with the clear-margin group, the involved-margin group showed a significantly lower rate of RFS ( $82 \%$ vs. $43 \%$; $=0.03$; Fig. 1 ).

In this study, 2 patients died because of recurrence accompanied by anaplastic change during follow-up. Since the mortality rate was so low, it was difficult to evaluate the factors associated with survival.

\section{Discussion}

Although most patients with well-differentiated thyroid carcinomas have excellent prognoses with very low mortality rates, several staging systems for thyroid cancer have acknowledged the negative prognostic impact of local invasion ${ }^{1,9}$. In such cases, the death rate significantly increases to $5 \sim 35 \%{ }^{10}$. In this regard, RLN involvement is a poor prognostic factor for T4a PTC patients. In this study, 18 patients $(25 \%)$ relapsed and $2(3 \%)$ died of anaplastic cancer after relapse. This recurrence rate was comparable to that of previous results. Chen et al. ${ }^{5}$ showed that recurrence occurred in $31.4 \%$ of patients in the RLN invasion group; this value was 3 times higher than that of the control group (10.3\%).

RLN invasion due to thyroid cancer can be predicted by the presence of VCP before surgery ${ }^{11}$. However, RLN involvement is frequently identified intraoperatively. In this study, RLN invasion was confirmed in $48.6 \%$ of patients during surgery. Table 2 shows that there was no significant difference in the rate of recurrence between the preoperative VCP group and the intraoperative RLN-invasion group $(27.0 \%$ and $22.9 \%$, respectively).

The RLN may be sacrificed in cases of invasion or it can be preserved by shaving. In this study, 31 (83.8\%) patients with preoperative VCP and 16 (45.7\%) without preoperative VCP underwent nerve resection. Among the patients in whom the RLN was sacrificed, $14.7 \%$ underwent nerve anastomosis 
during surgery and $27.7 \%$ received phono-surgery (e.g., injection laryngoplasty) at follow-up. To date, it is controversial whether the nerve should be preserved or sacrificed in PTC patients with RLN involvement. Nishida et al. ${ }^{12}$ suggested that it is worthwhile to preserve the RLN, even if it is infiltrated by differentiated thyroid cancer because postoperative vocal cord function can be maintained without affecting the incidence of local recurrence or overall prognosis. Similarly, in a univariate analysis by Lang et al. ${ }^{13}$, RLN resection did not emerge as a significant predictor for cancer-specific survival. In our study, RLN was sacrificed intraoperatively in 47 patients (65.3\%) and shaved in 25 (34.7\%). This was consistent with the results of previous studies because there was no significant difference in the RFS with or without nerve resection $(p=0.143)$. Therefore, these results suggest that in cases of RLN invasion, the PTC recurrence rate is not affected by whether the nerve is resected or preserved by shaving.

In patients with of RLN invasion, the trachea and esophagus were involved in $18.1 \%$ and $20.8 \%$ of patients, respectively. These invasions were higher in the preoperative VCP group as compared to the intraoperative RLN-invasion group ( $24.3 \%$ vs $11.4 \% ; 24.3 \%$ vs $17.1 \%)$, but this difference was not statistically significant. The recurrence rates of tracheal and esophageal involvement were $30.77 \%$ and $33.33 \%$, respectively (Table 1 ). There was a higher recurrence rate in these patients than that of patients whose organs were not affected, but this was not a statistical difference $(p>0.05)$. These results suggest that tracheal and esophageal invasion may lead to a poor prognosis, but do not affect recurrence in patients with RLN invasion. A report by Kim et al. ${ }^{8}$ that included 96 locally invasive PTC patients showed results that were consistent with our study, in that they found no relationship between the recurrence rates and tracheal, laryngeal, and esophageal involvement.

The Kaplan-Meier survival curve indicated that the risk of recurrence was significantly higher in the group with positive resection margins compared to the group without positive resection margins (as per both univariate and multivariate analyses) (Table 3 ). Complete tumour resection is important for the prognosis of PTC patients. According to the most recent American Thyroid Association guideline, incomplete resection is a high-risk factor for tumour recurrence. Several studies on microscopic positive tumour margins have reported that there is no association with recurrence. ${ }^{14-16}$ Recently, Abraham et al. ${ }^{17,18}$ reported that microscopic positive tumour margins did not affect disease-free survival in the majority of patients with PTC, but was associated with a four-fold increased risk of recurrence in T4a patients. This supports the results of our study, which was conducted among T4a patients with RLN involvement.

Several studies have investigated the association between clinical factors and the prognosis of PTC with RLN invasion. A multivariate analysis conducted by Ito et al. ${ }^{19}$, found that the significant extension of PTC to other organs was strongly predictive of distant recurrence and mortality. Kim et al. ${ }^{8}$ reported that the post-ablation-stimulated $\mathrm{Tg}$ level was an independent predictor of recurrence in multivariate analysis. On the other hand, Lee et al. ${ }^{20}$ reported that none of the investigated factors had a significant correlation with recurrence in patients with locally invasive PTC and the exclusive involvement of a functioning RLN. In this study, the major factors affecting the prognosis of PTC patients with RLN invasion were the status of the resection margin and the number of central neck LN metastases (according to univariate analysis). 
In the multivariate analysis, resection margin involvement was the only factor that predisposed to a high recurrence rate. Invasion to other organs and post-ablation-stimulated Tg levels were not significant predictors of PTC recurrence. Similar studies were conducted in the past, but this is a new finding $\mathrm{n}$ this study that the resection margin status is a major prognostic factor in PTC patients with RLN invasion.

There are some limitations to this study. First, we did not assess the correlation between the site of diagnosis, presence of a positive margin, and the site of recurrence. Second, the status of the RLN was based on surgical findings and the decision of the surgeon, and not intraoperative neuromonitoring (IONM). A recently published guideline has promoted the use of IONM to determine whether the RLN should be preserved or sacrificed when invaded by PTC ${ }^{21}$. As the use of IONM in thyroid surgery has been recently limited to select cases by the Korean medical insurance system, this technique was not applied in the majority of patients. We recommend that large-scale, multi-centre, prospective studies with a careful follow-up schedule be designed in the future to address all these limitations and further validate our results.

The prognosis of T4a PTC patients with RLN involvement was relatively poor, and the recurrence rate was not affected by preoperative VCP, intraoperative detection of RLN invasion, nerve resection, nerve preservation by shaving, LN metastasis, or tracheal or esophageal invasion. The most important prognostic factor for recurrence was a positive resection margin.

\section{Materials And Methods}

From January 2004 to December 2017, we retrospectively reviewed all patients who underwent thyroidectomy at the Department of Otorhinolaryngology, Head and Neck Surgery at the Pusan National University Hospital in Busan, Republic of Korea. During this period, 3345 patients underwent thyroid surgery at our institution. We included PTC patients with preoperative VCP or those showing postoperative VCP with intraoperatively confirmed RLN invasion. We excluded patients who presented with other types of thyroid cancer, i.e., follicular, medullary, anaplastic carcinoma, and those who had VCP due to a traction injury. Using these criteria, we considered 72 patients eligible for our study.

The patients underwent three types of surgery: hemithyroidectomy, total thyroidectomy with central neck dissection, and total thyroidectomy with central neck dissection. A majority of patients underwent a preoperative ultrasound of the thyroid, voice laboratory tests, and a thyroidectomy-related voice questionnaire. We checked the vocal movements of all patients before surgery using a laryngoscope.

The criteria for determining RLN invasion during surgery were: (1) a patient showing nerve involvement as a postoperative pathology, (2) an RLN surrounded by tumours, (3) nerves being non-identifiable due to gross extrathyroidal extension (ETE), and (4) the tumour being directly adherent to the nerve. The criteria for determining tumour recurrence were: (1) if PTC recurrence was confirmed by a postsurgical pathology following re-surgery, (2) the patient was not operated upon but showed recurrence on an ultrasound- 
guided biopsy performed to check suspected recurrence during the follow-up, (3) if metastatic cancer recurrence was suspected on positron emission tomography-computed tomography (CT) and chest CT.

Statistical analysis was performed using the R 3.6.2 software for Windows. Depending on whether or not normality was satisfied, we subjected the continuous variables to an independent $t$-test or Wilcoxon ranksum test and the Fisher's exact test. In the survival analysis, we used the Kaplan-Meier method to estimate the recurrence rate and the Cox proportional hazards model to test the significance.

This study was approved by the Pusan National University Hospital Institutional Review Board (IRB number: H-2004-003-089), which is organized and operates according to ICH-GCP and the applicable laws and regulations. By the Pusan National University Hospital IRB, the need for informed consent was waived for this study because the data has been provided from which personal identification information has been deleted and analyzed retrospectively, such as simple charts and image reviews.

\section{Declarations}

\section{Author Contributions}

H.S.N. data collection and manuscript writing. S.C.S., H.K.K., Y.I.C. and M.S. data analysis. J.C.L., E.S.S. and M.L. interpretation of data. I.J.K. and B.H.K. manuscript review. B.J.L. conception and design of the work, interpretation of data and editing of the manuscript.

\section{Additional Information}

\section{Competing Interests}

The authors have no funding, financial relationships, or conflicts of interest to disclose.

\section{Data Availability:}

The datasets are not publicly available due to protection of patient information but are available from the corresponding author on reasonable request.

\section{References}

1. Yi KH. The Revised 2016 Korean Thyroid Association Guidelines for Thyroid Nodules and Cancers: Differences from the 2015 American Thyroid Association Guidelines. Endocrinol Metab (Seoul) 2016; 31:373-378.

2. Haugen BR, Alexander EK, Bible KCet al. 2015 American Thyroid Association Management Guidelines for Adult Patients with Thyroid Nodules and Differentiated Thyroid Cancer: The American Thyroid Association Guidelines Task Force on Thyroid Nodules and Differentiated Thyroid Cancer. Thyroid 2016; 26:1-133. 
3. Metere A, Aceti V, Giacomelli L. The surgical management of locally advanced well-differentiated thyroid carcinoma: changes over the years according to the AJCC 8th edition Cancer Staging Manual. Thyroid Res 2019; 12:10.

4. Tumino D, Frasca F, Newbold K. Updates on the Management of Advanced, Metastatic, and Radioiodine Refractory Differentiated Thyroid Cancer. Front Endocrinol (Lausanne) 2017; 8:312.

5. Chen W, Lei J, You Jet al. Predictive factors and prognosis for recurrent laryngeal nerve invasion in papillary thyroid carcinoma. Onco Targets Ther 2017; 10:4485-4491.

6. Chiang FY, Lin JC, Lee KWet al. Thyroid tumors with preoperative recurrent laryngeal nerve palsy: clinicopathologic features and treatment outcome. Surgery 2006; 140:413-417.

7. Kay-Rivest E, Mitmaker E, Payne RJet al. Preoperative vocal cord paralysis and its association with malignant thyroid disease and other pathological features. J Otolaryngol Head Neck Surg 2015; 44:35.

8. Kim JW, Roh JL, Gong Get al. Treatment Outcomes and Risk Factors for Recurrence After Definitive Surgery of Locally Invasive Well-Differentiated Papillary Thyroid Carcinoma. Thyroid 2016; 26:262270.

9. Honings J, Stephen AE, Marres HA, Gaissert HA. The management of thyroid carcinoma invading the larynx or trachea. Laryngoscope 2010; 120:682-689.

10. Chan WF, Lo CY, Lam KY, Wan KY. Recurrent laryngeal nerve palsy in well-differentiated thyroid carcinoma: clinicopathologic features and outcome study. World J Surg 2004; 28:1093-1098.

11. Moritani S. Impact of lymph node metastases with recurrent laryngeal nerve invasion on patients with papillary thyroid carcinoma. Thyroid 2015; 25:107-111.

12. Nishida T, Nakao K, Hamaji M, Kamiike W, Kurozumi K, Matsuda H. Preservation of recurrent laryngeal nerve invaded by differentiated thyroid cancer. Ann Surg 1997; 226:85-91.

13. Lang BH, Lo CY, Wong KP, Wan KY. Should an involved but functioning recurrent laryngeal nerve be shaved or resected in a locally advanced papillary thyroid carcinoma? Ann Surg Oncol 2013; 20:2951-2957.

14. Hong CM, Ahn BC, Park JY, Jeong SY, Lee SW, Lee J. Prognostic implications of microscopic involvement of surgical resection margin in patients with differentiated papillary thyroid cancer after high-dose radioactive iodine ablation. Ann Nucl Med 2012; 26:311-318.

15. Hartl DM, Zago S, Leboulleux Set al. Resection margins and prognosis in locally invasive thyroid cancer. Head Neck 2014; 36:1034-1038.

16. Wang LY, Nixon IJ, Patel SGet al. Operative management of locally advanced, differentiated thyroid cancer. Surgery 2016; 160:738-746.

17. Abraham E, Tran B, Roshan Det al. Microscopic positive margins in papillary thyroid cancer do not impact disease recurrence. ANZ J Surg 2018; 88:1193-1197.

18. Abraham E, Roshan D, Tran Bet al. Microscopic positive margins strongly predict reduced diseasefree survival in pT4a papillary thyroid cancer. Head Neck 2019; 41:2549-2554. 
19. Ito Y, Kihara M, Takamura Y, Kobayashi K, Miya A, Miyauchi A. Prognosis and prognostic factors of patients with papillary thyroid carcinoma requiring resection of recurrent laryngeal nerve due to carcinoma extension. Endocr J 2012; 59:247-252.

20. Lee HS, Kim SW, Park T, Nam GY, Hong JC, Lee KD. Papillary thyroid carcinoma with exclusive involvement of a functioning recurrent laryngeal nerve may be treated with shaving technique. World J Surg 2015; 39:969-974.

21. Wu CW, Dionigi G, Barczynski Met al. International neuromonitoring study group guidelines 2018 : Part II: Optimal recurrent laryngeal nerve management for invasive thyroid cancer-incorporation of surgical, laryngeal, and neural electrophysiologic data. Laryngoscope 2018; 128 Suppl 3:S18-S27.

\section{Figures}

resection_margin

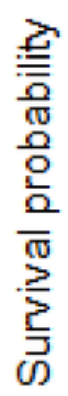

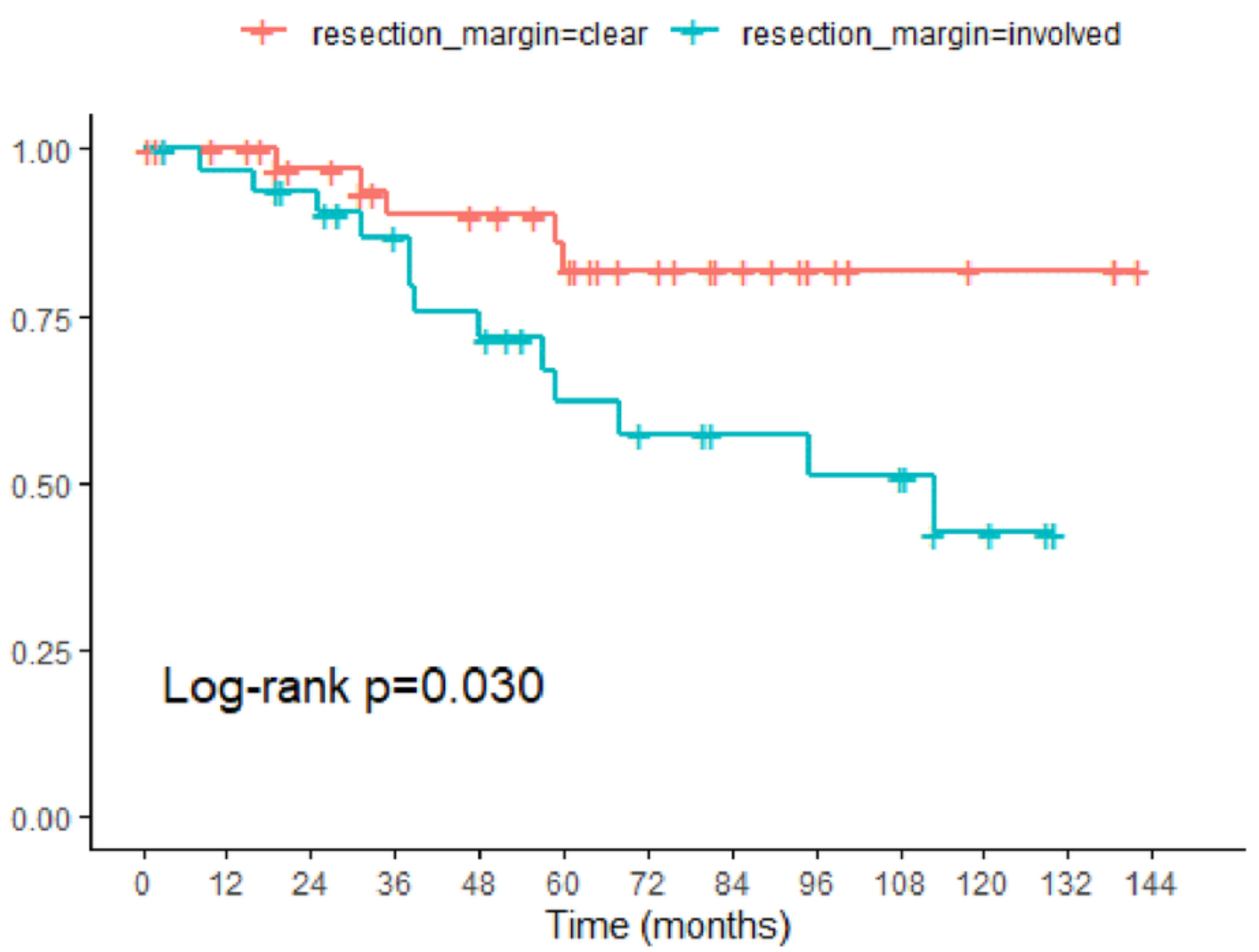

resection_margin

$\begin{array}{llllllllllllll}\text { resection_margin=clear } & 39 & 35 & 30 & 25 & 24 & 21 & 15 & 9 & 5 & 3 & 2 & 2 & 0\end{array}$

$\begin{array}{llllllllllllll}\text { resection_margin=involved } & 33 & 31 & 28 & 24 & 20 & 13 & 11 & 9 & 8 & 8 & 3 & 0 & 0\end{array}$

Figure 1 
A Kaplan-Meier survival curve showing the overall recurrence-free survival of patients with a resectionmargin status. 